\title{
COVID-19 - Estratégias para se manter fisicamente ativo e seguro dentro de casa
}

\author{
Erivelton Fernandes França ${ }^{1,2}$ \\ Gabrielle Mitico Miyake ${ }^{3}$ \\ João Pedro da Silva Júnior ${ }^{4}$ \\ Victor Keihan Rodrigues Matsudo 4 \\ Rodrigo Álvaro Brandão Lopes Martins ${ }^{5}$ \\ Fábio Dupart Nascimento ${ }^{1}$
}

Em 12 dezembro de 2019, na cidade de Wuhan situada na China, foi verificado o primeiro caso de Síndrome Respiratória Aguda Grave Coronavirus 2 (SARSCoV-2). Este vírus é o causador da patologia denominada pela Organização Mundial da Saúde (OMS) como COVID-19. A sigla COVID deriva do inglês Corona Vírus Disease, já o numeral 19 faz alusão ao ano em que foram divulgados publicamente pelo governo chinês os primeiros casos da doença.

Cabe ressaltar que esta denominação tem por objetivo, além da classificação médica, dirimir possíveis casos de xenofobia e preconceito, sobretudo com a população de origem asiática. Segundo a OMS, na grande maioria dos casos (aproximadamente 80\%) o COVID-19 pode ser assintomático. Em contrapartida, por apresentarem dificuldade respiratória, cerca de $20 \%$ dos casos requerem atendimento hospitalar. Destes, por volta de $5 \%$ necessitam de suporte ventilatório para o tratamento de insuficiência respiratória [1,2].

Tendo como principal grupo de risco indivíduos com doenças crônicas como hipertensão, diabetes, doenças respiratórias e idade superior a 60 anos, o tratamento do COVID-19 é extremamente complexo, pois além de não haver ainda um fármaco eficiente no tratamento da doença, esta patologia viral apresenta diferentes manifestações clínicas [3]. A depender do quadro no qual o indivíduo infectado se encontra, o mesmo poderá ser classificado em 4 estágios, neste caso, leve, moderado, grave e crítico. As características centrais para cada um destes estágios são: 1) leve: sem dispneia, sem baixa saturação de oxigênio no sangue (SatO2), com presença ou não de picos febril, perda de olfato e paladar; 2) moderado: dispneia em pequenos e médios esforços físicos, SatO2 94\% a 98\% e sinais radiológicos de pneumonia; 3) grave: dispneia, SatO2 $\leq 93 \%$, com frequência respiratória (FR)> 30/min, progressão radiológica das lesões, necessidade de suplementação de $\mathrm{O} 2$, eventualmente com ventilação não invasiva; e 4) crítico: os pacientes necessitam de ventilação mecânica [3].

No que tange a transmissão do COVID-19, evidências científicas apontam que as principais maneiras de contaminação da doença ocorrem por meio da

\footnotetext{
${ }^{1}$ Núcleo de Pesquisas Tecnológicas (NPT) da Universidade de Mogi das Cruzes (UMC). Mogi das Cruzes - SP, Brasil. Email: erivelton.fernandes@hotmail.com

${ }^{2}$ Centro Universitário Carlos Drummond de Andrade (Unidrummond). São Paulo - SP, Brasil.

${ }^{3}$ Universidade de São Paulo (USP). São Paulo - SP, Brasil.

${ }^{4}$ Centro de Estudos do Laboratório de Aptidão Física de São Caetano do Sul (CELAFISCS). São Caetano do Sul - SP, Brasil.

${ }^{5}$ Universidade do Vale do Paraíba (UNIVAP). São José dos Campos - SP, Brasil.
}

Como citar este artigo / How to cite this article

França EF, Miyake GM, da Silva Junior JP, Matsudo VKR, Martins RABL, Nascimento FD. COVID-19 - Estratégias para se manter fisicamente ativo e seguro dentro de casa. InterAm J Med Health 2020;3:e202003034. 
disseminação respiratória de pessoa para pessoa (pessoas em contato próximo ou através de gotículas respiratórias produzidas quando uma pessoa infectada tosse ou espirra) e em menor nível, do contato com pessoas contaminadas, superfícies ou objetos [4]

Neste sentido, com o intuito de evitar mais mortes ocasionadas pela pandemia de COVID-19, devido um colapso dos sistemas públicos de saúde, autoridades sanitárias e governantes de todo o mundo, após ter sido decretado no dia 11 de Março de 2020 pela OMS a Pandemia de coronavirus (quando houve mais de 115 países com casos declarados de infeça), optaram por uaises com política uma polftica de isolamento social que pode ser menos restritiva, neste caso, a denominada quarentena, ou com maior restrição, o chamado lockdown (em português: confinamento) [5]

Inevitavelmente, as medidas restritivas adotadas com o intuito de conter o número de mortes por COVID-19, estão afetando drasticamente o nível de atividade física populacional. Isso está ocorrendo, pois além de muitos trabalhadores estarem desempenhando suas atividades laborais no modo home office (em português: trabalho em (asa), os espaços tipicamente destinados a prática de atividades físicas como academias e parques públicos estão fechados, o que dificulta a prática de atividade física. Apesar disso, tendo em vista a importância de um estilo de vida ativo para a manutenção da saúde, o American College of Sports Medicine juntamente com a OMS tem estimulado a prática de atividade física em casa [6] Sendo assim, em razao da altíssima relesinca do tema, este breve artigo tem como objetivo dar sugestos pontuais que ampliem as possibilidades da prática de atividade física dentro de casa durante a pandemia de COVID-19.

Antes de abordar as sugestões para a prática de atividade física vale revisar algumas definições $e$ recomendações relacionadas à atividade física. Podemos entender atividade física como qualquer movimento corporal realizado voluntariamente através de contração da musculatura esquelética, que eleve o gasto energético para além dos níveis de repouso. Essa definição fo elaborada por Carpensen e colaboradores [7] e é adotada até os dias atuais pela OMS. Dessa forma, os mais variados movimentos realizados em diferentes contextos (lazer, trabalho, locomoção e atividades domésticas) quando exigem um gasto calórico maior do que em estado basal, mo atividades físicas [7].

É muito comum que os termos atividade física e exercício físico sejam utilizados como sinônimos, entretanto isso é um equívoco. Esse erro ocorre pelo fato da prática de exercício físico ser uma das subcategorias das atividades físicas, e por ambos terem como característica central a realização de movimentos corporais que demandam um gasto energético maior do que em estado de repouso. Entretanto, o fator chave que diferencia esses dois termos é que o exercício físico é realizado de forma sistematizada e estruturada, com objetivos específicos em relação à aptidão física, seja ela esportiva ou relacionada à saúde [7]. Por aptidão física, entendemos a capacidade de um indivíduo realizar atividades físicas e/ou exercícios físicos com vigor e disposição. Dessa maneira, quanto menor for o esforço de um indivíduo na realizaça de uma tarefa, aptidão física [8].

Em se tratando de recomendações para a prática de atividades físicas, a OMS sugere que as crianças e jovens com faixa etária de 5 a 17 anos realizem 60 minutos diários de atividades físicas aeróbicas (atividades contínuas, geralmente de longa duração e intensidade de baixa a moderada, que utilizam grandes grupos musculares, aumentando o consumo de oxigênio pelo organismo e também o metabolismo de gorduras, principal fonte energética durante a atividade) com intensidade moderada a vigorosa, além de exercícios físicos para o fortalecimento muscular e ósseo, três vezes por semana. Para adultos e idosos, a recomendação semanal de exercícios aeróbios é de 75 minutos se forem em intensidade vigorosa e 150 minutos para intensidade moderada, com no mínimo 2 sessões de treino destinadas ao fortalecimento muscular [9]. Isto posto, as sugestões deste artigo para a prática de atividade física durante o isolamento social decretado pela pandemia de COVID-19 serão abordadas no quadro abaixo.
Quadro 1- Atividades físicas sugeridas durante o isolamento social decretado pela pandemia de COVID-19.

\begin{tabular}{|c|c|}
\hline Atividade física sugerida & Benefícios e observações \\
\hline Dança & $\begin{array}{l}\text { A dança é uma excelente atividade física aeróbica, melhora a disposição para as atividades diárias } \\
\text { e pode proporcionar ao praticante, força muscular, melhora da autoestima/motivação e benefí- } \\
\text { cios relacionados à estética corporal [10]. } \\
\text { Independente do nível de proficieincia em alguma modalidade de dança o indivíduo poderá } \\
\text { utilizar vídeos para imitar os passos e coreografias. Outro ponto importante, é que esta atividade } \\
\text { fisica poderá ser realizada inclusive em moradias menores com maior limitação de espaço, como } \\
\text { é característico na grande maioria dos apartamentos. }\end{array}$ \\
\hline Exergames (jogos ativos) & $\begin{array}{l}\text { Os jogos ativos ou exergames estimulam a atividade física por meio de sensores de movimento } \\
\text { presentes em alguns videogames. Essa característica tem tornado os exergames uma alternativa } \\
\text { promissora para o aumento nos niveis de atividade física, especialmente para crianças e adoles- } \\
\text { centes que apresentam grande interesse por jogose eletronnicos [11]. } \\
\text { Na ausência de um videogame em casa, uma alternativa interessante são os jogos e brincadeiras } \\
\text { da cultura popular como amarelinha, pular corda, dentre outros. }\end{array}$ \\
\hline Atividades domésticas & $\begin{array}{l}\text { Os afazeres domésticos representam uma boa parte do gasto energético diário com atividade } \\
\text { física. Logo, além de crucial para a organizaçãa e limpeza domiciliar são altamente recomendadas } \\
\text { durante este período de quarentena [6,7]. } \\
\text { Neste momento, utilizar hábitos antigos como lavar roupas a mão e limpar os móveis sem a uti- } \\
\text { lização de recursoso tecnológicos como o aspirador de pó, poderão contribuir para a manutenção } \\
\text { mínima da prática de atividade física. }\end{array}$ \\
\hline $\begin{array}{l}\text { Brincar com os pets (animais } \\
\text { de estimação) }\end{array}$ & $\begin{array}{l}\text { A relação afetiva estabelecida entre a pessoa e o seu animal de estimação é de suma importância } \\
\text { para estimulação da prática de atividade física. Em proprietários de cachorros, especificamente, já } \\
\text { está bem documentada a influência positiva dos pets sobre o gasto calórico diário destes [12]. } \\
\text { Um estudo clássico publicado em } 1980 \text { por Friedmanne e colaboradores com pacientes acometi- } \\
\text { dos por infarto agudo do miocárdio, evidenciou que a taxa anual de sobrevida nestes foi relativa- } \\
\text { mente maior nos que possuriam animais de estimação (72\% versus } 94 \% \text { ) [13]. }\end{array}$ \\
\hline $\begin{array}{l}\text { Exercícios de } \\
\text { alongamento }\end{array}$ & $\begin{array}{l}\text { Já está muito bem descrito que os exercícios de alongamento muscular são extremamente bené- } \\
\text { ficos para reduzir o estresse ocupacional. Dentre os mecanismos fisiológicos atrelados a estes } \\
\text { benefícicos podemos citar o aumento da vascularização sanguinea que ocorre devido à estimula- } \\
\text { ção mecânica oriunda dos exercícios realizados, o que pode atenuar e/ou evitar dores osteomus- } \\
\text { culares em regiōes como a coluna cervical e lombar [14]. } \\
\text { Tendo em vista o grande número de profissionais que aderiram ao modo de trabalho home of- } \\
\text { fice, realizar pequenas pausas na rotina laboral com a realização de exercícios de alongamento } \\
\text { poderá dirimir os efeitos nocivos das várias horas de trabalho sedentário. Caso o indivíduo não } \\
\text { seja familiarizado com esta prática, vários exemplos poderão ser encontrados facilmente na } \\
\text { internet. }\end{array}$ \\
\hline Academias online (conectadas) & $\begin{array}{l}\text { Apesar das academias e demais locais para a prática de atividades físicas estarem fechados } \\
\text { durante esta pandemia [15], devido ao compromisso com a promoção de saúde por meio da } \\
\text { prescrição de exercícios físicos, bem como a necessidade de manutenção da renda familiar e } \\
\text { pagamento de funcionários, diversas academias e profissionais de Educação Fisica autônomos } \\
\text { têm ministrado aulas remotas com preços acessiveris. Estas aulas ofertadas variam de exercícios } \\
\text { físicos de menor intensidade, como Yoga e Tai Chi Chuan a programas mais intensos como o } \\
\text { denominado Fitness Dance e o Cross Training. }\end{array}$ \\
\hline
\end{tabular}


Não é pretensão deste breve artigo elucidar o 3 3. Ornetti, P., Fortunet, C., Morisset, C., Grémeaux, V., problema da inatividade física influenciada pela pandemia Maillefert, J., F, Casillas, J., M, \& Laroche, D. (2015). (a) protocolo de exercícios físicos ou muito a discussão em torno do tema Pelo contrário, este physical and rehabilitation medicine, 58(3), 126-131. manuscrito tem como meta contribuir para a eliminação das possíveis barreiras impostas para a prática de atividade 4. Huang, C., Wang, Y., Li, X., Ren, L., Zhao, J., Hu, Y., ... \& Cheng, física durante este, necessário, isolamento social. Isso nos Z. (2020). Clinical features of patients infected with 2019 novel fez pensar em atividades simples que permitam manter coronavirusinWuhan, China. Thelancet,395(10223),497-506. fisicamente ativo os mais variados públicos etários e socioeconômicos. Ademais, diversas outras estratégias simples não mencionadas neste trabatho podem ser consideradas, tais como a redução de tempo sentado que por si só já traz benefícios à saúde [16]. Cabe ainda ressaltar que diversos pesquisadores em todo o mundo tem trazido contribuições científicas muito pertinentes sobre esta temática. A respeito, vale citar o trabalho de Nogueira e colaboradores (2020), pesquisador brasileiro, que escreveu um excelente artigo de revisão integrativa da literatura sobre as recomendações para a prática de exercício físico em face do COVID-19 [17].

Por fim, apesar de não haverem ainda na literatura trabalhos que comprovem o efeito profilático da prática de exercícios físicos sobre o COVID-19. Sabe-se que exercícios físicos regulares em intensidade leve a moderada trazem benefícios ao sistema imunológico, pois dentre vários fatores, melhoram a resposta leucocitária na infecção por patógenos [18] Sendo assim, levando em consideração individualidade biológica e os cul a individualdade buogica e os culdados minimos para uma prática segura e regular de alividades fisicas e exercícios físicos que poderão ser melhor orientados po um profissional de Educação Física, é sensato combater o sedentarismo imposto pelo isolamento do COVID-19 em todos os públicos e faixas etárias, preferencialmente, na segurança e aconchego do lar.

\section{REFERÊNCIAS}

1. Zhang, H., Penninger, J. M., Li, Y., Zhong, N., \& Slutsky, A. S. (2020). Angiotensin-converting enzyme 2 (ACE2) as a SARS-CoV-2 receptor: molecular mechanisms and potential therapeutic target. Intensive care medicine, 1-5.

2. Zhang, J. J, Dong, X, Cao, Y, Y, Yuan, Y D., Yang Y B, , Yan, Y. Q..... \& Gao, Y. D. (2020). Clinical characteristics of 140 patients infected with SARS-CoV-2 in Wuhan, China. Allergy.
5. Frühauf, A., Schnitzer, M., Schobersberger, W., Weiss, G., \& Kopp, M. (2020). Jogging, nordic walking and going for a walk-inter-disciplinary recommendations to keep people physically active in times of the covid-19 lockdown in Tyrol, Austria. Current Issues in Sport Science (CISS). 6. Medicine AAC of $\mathrm{S}$. Staying Physically Active During the COVID-19 Pandemic [Internet]. 2020 [cited 2020 May 8]. p. 2. Available from: https://www.acsm.org/readresearch/newsroom/news-releases/news-detai/2020/03/16/ staying-physically-active-during-covid-19-pandemic

7. Caspersen, C. J., Powell, K. E., \& Christenson, G M. (1985). Physical activity, exercise, and physical fitness: definitions and distinctions for healthrelated research. Public health rep, 100(2), 126-31.

8. Pate, R. R. (1988). The evolving definition of physical fitness. Quest, 40(3) 174-179.

9. Hammami, A, Harrabi, B, Mohr, M, \& Krustrup, P. (2020). Physical activity and coronavirus disease 2019 (COVID-19): specific recommendations for home-based physical training. Managing Sport and Leisure, 1-6.

10. Joung, HJ, \& Lee, Y. (2019). Effect of Creative Dance on Fitness, Functional Balance, and Mobility Control in the Elderly. Gerontology, 65(5), 537-546.

11. Medeiros, P. D., Capistrano, R., Zequinão, M. A., Silva, S. A. D., Beltrame, T. S., \& Cardoso, F. L. (2017). Exergames como ferramenta de aquisição e desenvolvimento de habilidades e capacidades motoras: uma revisão sistemática. Revista Paulista de Pediatria, 35(4), 464-471.

12. Levine, G.N.,Allen, K., Braun, L.T., Christian, H.E.,Friedmann, E., Taubert, K. A.,... \& Lange, R. A. (2013). Pet ownership and cardiovascular risk: a scientific statement from the American Heart Association. Circulation, 127(23), 2353-2363.

13. Friedmann, E., Katcher, A. H., Lynch, J. J., \& Thomas, S. A. (1980). Animal companions and oneyear survival of patients after discharge from a coronary care unit. Public health reports, 95(4), 307.

14. Wongwilairat, K., Buranruk, O., Eungpinichpong, W. Puntumetakul, R., \& Kantharadussadee-Triamchaisri, S. (2018). Alongamento muscular com padrões de respiração profunda (n)

15. Miguel, H. (2020). Impactos da Covid-19 sobre o Personal Trainer. InterAmerican Journal of Medicine and Health, 3.

16. Jakobsson, J., Malm, C., Furberg, M., Ekelund, U., \& Svensson, M. (2020). Physical Activity During the Coronavirus (COVID-19) Pandemic: Prevention of a Decline in Metabolic and Immunological Functions. Frontiers in Sports and Active Living, 2, 57.

17. Nogueira, C. J., Cortez, A. C. L., de Oliveira Leal, S. M., \& Dantas, E. H. M. Precauções e recomendações para a prática de exercício físico em face do COVID-19: uma revisão integrativa.

18. Pitanga, F. J. G., Beck, C. C., \& Pitanga, C. P. S (2020). Atividade Física e Redução do Comportamento Sedentário durante a Pandemia do Coronavírus. Arquivos Brasileiros de Cardiologia, (AHEAD). 